PENULTIMATE DRAFT - PLEASE CITE THE PUBLISHED VERSION

To appear in: Bangu, S. (ed.), Naturalizing Logico-Mathematical Knowledge, Routledge.

\title{
Mathematical Knowledge, the Analytic Method, and Naturalism
}

\author{
Fabio Sterpetti \\ Campus Bio-Medico University of Rome; Sapienza University of Rome
}

\section{The Problem of Mathematical Knowledge}

It is often argued that mathematics is "the paradigm of certain and final knowledge" (Feferman 1998, 77). The degree of certainty that mathematics is able to provide is considered one of its qualifying features by many authors. For example, Byers states that the certainty of mathematics is "different from the certainty one finds in other fields [...]. Mathematical truth has [...] [the] quality of inexorability. This is its essence" (Byers 2007, 328).

It is also often claimed that mathematics is objective, in the sense that it is mind-independent, and so that it is independent from our biological constitution. For example, George and Velleman state that understanding the nature of mathematics does not require asking "such questions as "What brain, or neural activity, or cognitive architecture makes mathematical thought possible?'," because "such studies focus on phenomena that are really extraneous to the nature of mathematical thought itself" (George, Velleman 2002, 2).

Mathematics proved tremendously useful in dealing with the world. Indeed, current natural science is "mathematical through and through: it is impossible to do physics, chemistry, molecular biology, and so forth without a very thorough and quite extensive knowledge of modern mathematics" (Weir 2005, 461). But despite its being so pervasive in scientific knowledge, we do not have yet an uncontroversial and science-oriented account of what mathematics is. So, "in a reality [...] understood by the methods of science," we are unable to answer to the following question: "where does mathematical certainty come from?", even because most mathematicians and scientists "do not take seriously the problem of reconciling" the certainty of mathematical knowledge "with a scientific worldview" (Deutsch 1997, 240).

Moreover, many authors are skeptical about the very possibility of developing a naturalist perspective on mathematics. They think that "mathematics is an enormous Trojan Horse sitting firmly in the center of the citadel of naturalism," because even if "natural science is mathematical through and through," mathematics seems to "provide a counterexample both to methodological and to ontological naturalism." Indeed, mathematics ultimately rests on axioms, which are "traditionally held to be known a priori, in some accounts by virtue of a form of intuitive awareness." The epistemic role of the axioms in mathematics seems "uncomfortably close to that played by the insights of a mystic. When we turn to ontology, matters are, if anything, worse: mathematical entities, as traditionally construed, do not even exist in time, never mind space" (Weir 2005, 461-462). In 
fact, the majority of mathematicians and philosophers of mathematics argues for some form of mathematical realism (Balaguer 2009).

Thus, it is very difficult even to envisage how naturalistically accounting for what mathematics is and how we acquire mathematical knowledge. For example, Brown admits that he has "no idea how the mind is able to 'grasp' or 'perceive' mathematical objects and mathematical facts", but he nevertheless is certain that it "is not by means of some efficient cause" (Brown 2012, 12). The difficulty of accommodating mathematical knowledge within a coherent scientific world-view is what Mary Leng called 'the problem of mathematical knowledge'. According to her, "the most obvious answers to the two questions 'What is a human?' and 'What is mathematics?' together seem to conspire to make human mathematical knowledge impossible" (Leng 2007, 1). ${ }^{1}$

A clarification is in order. There is a huge number of works in cognitive science devoted to study numerical capacities in human and non-human animals (see e.g. Cohen Kadosh, Dowker 2015; Dehaene, Brannon 2011; Dehaene, Duhamel, Hauser, Rizzolatti 2005), but we will not be primarily concerned with these works here. Indeed, these researches do shed light on how to naturalistically conceive of mathematics (De Cruz 2006). But they have so far investigated the origin and functioning of some very basic numerical abilities. These basic capacities are thought to had evolved because they allow us to approximately deal with numerosities sufficiently well to ensure the survival. This seems insufficient to justify the claim that mathematical knowledge is certain. However, no adequate scientific account of how we develop advanced mathematics starting from those basic numerical abilities has been provided yet (see e.g. Spelke 2011). Thus, even if prima facie the study of such basic cognitive abilities does not support the traditional view of mathematics, it seems at the moment unable to definitely confute that view. Indeed, according to many authors that support the traditional view, throwing light on the evolutionary roots of these numerical capacities is, in and of itself, insufficient to naturalistically explain two things: first, the degree of certainty of mathematics; second, the effectiveness in dealing with the world that our advanced mathematics displays. For example, Polkinghorne states that it "seems clear enough that some very modest degree of elementary mathematical understanding [...] would have provided our ancestors with valuable evolutionary advantage. But whence has come the human capacity [...] to attain the ability to conjecture and eventually prove Fermat's Last Theorem, or to discover noncommutative geometry? Not only do these powers appear to convey no direct survival advantage, but they also seem vastly to exceed anything that might plausibly be considered a fortunate spin-off from such mundane necessity" (Polkinghorne 2011, 31-32). Since we are dealing here with the issue of whether the traditional view is compatible with a naturalist stance, as it will become more clear in what follows, we will not dwell on those attempts that try to naturalize mathematics by focusing on discoveries related to our basic numerical abilities,

1 On the difficulty of making the traditional view of mathematics compatible with a naturalist stance, cf. Núñez 2009, 69: "Lakoff and I called this view the romance of mathematics, a kind of mythology in which mathematics has a truly objective existence, providing structure to this universe and any possible universe, independent of and transcending the existence of human beings or any beings at all. However, despite its immediate intuitiveness and despite being supported by many outstanding physicists and mathematicians, the romance of mathematics is scientifically untenable." 
without addressing the issue of whether the traditional view of mathematics should be maintained or not in the light of our scientific understanding of those abilities.

This article aims to suggest that a promising step towards the elaboration of an adequate naturalist account of mathematics and mathematical knowledge may be to take the method of mathematics to be the analytic method rather than the axiomatic method. Indeed, it seems impossible to naturalize mathematics without challenging at least some crucial aspects of the traditional view of mathematics, according to which mathematical knowledge is certain and the method of mathematics is the axiomatic method. Nor does it seem possible to keep maintaining that the method of mathematics is the axiomatic method and mathematical knowledge is certain, if we dismiss that view. The analytic view of the method of mathematics, which has been mainly advocated by Carlo Cellucci in recent years (Cellucci forthcoming, 2017, 2013), will be illustrated in some detail; then, I will argue that this view could contribute to develop a naturalist account of mathematics and mathematical knowledge. I will also take Cellucci's insight further and point out that the analytic view of method can do that at a cost: it forces us to rethink the 'traditional image' of mathematics. Indeed, if we take the method of mathematics to be the analytic method, mathematical knowledge cannot be said to be certain, and the only kind of mathematical knowledge that we can have is plausible knowledge.

\section{The Method of Mathematics}

The certainty of mathematical knowledge is usually supposed to be due to the method of mathematics, which is commonly taken to be the axiomatic method. ${ }^{2}$ In this view, the method of mathematics differs from the method of investigation in the natural science: whereas "the latter acquire general knowledge using inductive methods, mathematical knowledge appears to be acquired [...] by deduction from basic principles" (Horsten 2015). According to Frege, when we do mathematics we form chains of deductive "inferences starting from known theorems, axioms, postulates or definitions and terminating with the theorem in question" (Frege 1984, 204). In the same vein, Gowers states that what mathematicians do is that they "start by writing down some axioms and deduce from them a theorem" (Gowers 2006, 183). So, it is the deductive character of mathematical demonstrations that confers its characteristic certainty to mathematical knowledge, since demonstrative "reasoning is safe, beyond controversy, and final" (Pólya $1954, \mathrm{I}, \mathrm{v})$, precisely because it is deductive in character. In this view, "deductive proof is almost the defining feature of mathematics" (Auslander 2008, 62).

If the method of mathematics is the axiomatic method, mathematics mainly consists in deductive chains from given axioms. So, in order to claim that mathematical knowledge is certain, we have to know that those axioms are 'true', where 'true' is usually intended as 'consistent with each other'.

As well as the consistency of axioms, the problem of justifying our reliability about mathematics is also related to the problem of justifying our reliability about logic. Indeed, if we think that the method of mathematics is the axiomatic method,

2 Cf. Baker 2016, sec. 1: "it seems fair to say that there is a philosophically established received view of the basic methodology of mathematics. Roughly, it is that mathematicians aim to prove mathematical claims [...], and that proof consists of the logical derivation of a given claim from axioms." 
proving the reliability of deductive inferences is essential for claiming for the certainty of mathematical knowledge. For example, Franks states that in mathematics "deductive logic is the only arbiter of truth" (Franks 1989, 68).

Thus, there are two statements that we should be able to prove in order to safely claim that mathematical knowledge is certain: 1) axioms are consistent; 2) deduction is truth-preserving. Indeed, a deductive proof "yields categorical knowledge [i.e. knowledge independent of any particular assumption] only if it proceeds from a secure starting point and if the rules of inference are truthpreserving" (Baker 2016, sec. 2.2).

Now, while whether it is possible to deductively prove 2) is at least controversial (see e.g. Haack 1976; Cellucci 2006), it is uncontroversial that it is generally impossible to mathematically prove 1), i.e. that axioms are consistent, because of Gödel's results. ${ }^{3}$ Indeed, by Gödel's second incompleteness theorem, for any consistent, sufficiently strong deductive theory $\mathrm{T}$, the sentence expressing the consistency of $\mathrm{T}$ is undemonstrable in $\mathrm{T}$. Usually, those authors that despite this result maintain that mathematical knowledge is certain, make reference to a sort of faculty that we are supposed to possess, and that would allow us to 'see' that axioms are consistent. For example, Brown states that we "can intuit mathematical objects and grasp mathematical truths. Mathematical entities can be 'perceived' or 'grasped' with the mind's eye" (Brown 2012, 45).

This view has been advocated by many great mathematicians and philosophers. Detlefsen describes the two main claims of this view as follows: 1) "mathematicians are commonly convinced that their reasoning is part of a process of discovery, and not mere invention;" 2) "mathematical entities exist in a noetic realm to which the human mind has access," (Detlefsen 2011, 73). With respect to the ability of grasping mathematical truths, i.e. accessing the mathematical realm, this view traditionally assumes "a type of apprehension, noessis, which is characterized by its distinctly 'intellectual' nature. This has generally been contrasted to forms of aisthesis, which is broadly sensuous or 'experiential' cognition [...]." (Ibidem, 73). For example, Gödel states that "despite their remoteness from sense experience we do have something like a perception also of the objects of set theory, as is seen from the fact that the axioms force themselves upon us as being true" (Gödel 1947: 1990, 268).

The problem is that this view is commonly supported by authors that are antinaturalists. ${ }^{4}$ Hence, they do not take care of articulating a scientifically plausible account of how such 'intuition' may work or may have evolved. The following question then arises: Is it possible to naturalize the human ability to grasp mathematics and logic, and maintain the traditional view of mathematical knowledge, i.e. that mathematical knowledge is certain and the method of mathematics is the axiomatic method? In other words, how can we account for the reliability of mathematics and logic, if we accept the idea that they are both

3 Cf. Baker 2016, sec. 2.3: "Although these results apply only to mathematical theories strong enough to embed arithmetic, the centrality of the natural numbers (and their extensions into the rationals, reals, complexes, etc.) as a focus of mathematical activity means that the implications are widespread."

4 On the anti-naturalism of many of the supporters of this view, cf. e.g. Gödel 1951: 1995, 323: "There exists [...] an entire world consisting of the totality of mathematical truths, which is accessible to us only through our intelligence, just as there exists the world of physical realities; each one is independent of us, both of them divinely created." 
produced by humans and humans are evolved organisms (Schechter 2013; Smith 2012)?

There is no clear answer to this question. Some authors have tried to naturalize mathematics and logic relying on evolutionism (see De Cruz 2006; Krebs 2011; Woleński 2012). The main difficulties afflicting these approaches derive from the fact that they try to naturalize mathematics in a way that allow them to avoid the risk of being excessively revisionary on what we take mathematical knowledge to be. In other words, they try to show that mathematics rests on some evolved cognitive abilities, and that this evolutionary ground confers a degree of epistemic justification to the mathematics we actually do which is able to secure our convictions on what mathematical knowledge is. ${ }^{5}$

The fact is that it is not easy to defend the claim that evolution may provide the degree of justification needed to maintain the traditional view of mathematics as the paradigm of certain knowledge. Briefly, in order to claim that natural selection gave us the ability at attaining the truth with regard to mathematics, we should demonstrate that natural selection is an aimed-at-truth process. For example, Wilkins and Griffiths state that to "defeat evolutionary skepticism, true belief must be linked to evolutionary success in such a way that selection will favour organisms which have true beliefs" (Wilkins, Griffiths 2013, 134). The problem is exactly how to justify such a link, and the issue is at least controversial (Vlerick, Broadbent 2015; Sage 2004).

Consider our confidence in the fact that deduction is truth-preserving. Kyburg states that "our justification of deductive rules must ultimately rest, in part, on an element of deductive intuition: we see that M[odus] $\mathrm{P}$ [onens] is truth-preserving this is simply the same as to reflect on it and fail to see how it can lead us astray" (Kyburg 1965, 276). The problem is that our failing to conceive an alternative can justify the reliability of the deductive rules only if our ability to conceive alternatives could be shown to reliably exhaust the space of all the possible alternatives. But such a demonstration of the reliability of our ability to conceive alternatives doesn't exist, and we can rely only on our 'intuition' (i.e. on our failing in finding any counter-example) to convince ourselves that MP cannot lead us astray, and on the fact that such 'intuition' appears self-evident to us. ${ }^{6}$ The mere fact that some statements appear to us as self-evidently true it is not by itself a guarantee of their truth, if our ability in evaluating the self-evident truth of a statement is an evolved capacity. Our 'sense' of the self-evident may be not only oriented towards contingent connections which were useful in the past and that do not reflect necessary and eternal truths, but given that we are not able to

5 Other proposals devoted to naturalize mathematics by considering our evolved cognitive abilities have been put forward by Núñez (2008; 2009) and Ye (2011). These interesting proposals cannot be discussed here for reason of space. What is nevertheless worth underlining here is that even if both these proposals, despite their full-blooded naturalism, seem to leave untouched the idea that the method of mathematics is the axiomatic method, they both explicitly claim that Mathematical Platonism is incompatible with a naturalist stance, because it is scientifically untenable. So, they cannot be regarded as naturalized versions of the traditional view.

6 Sklar (1981) argues that in fact we are unable to exhaustively explore the space of possible alternatives, given that in the past, as history of science teaches us, we routinely failed in exploring the space of the conceivable alternatives to a given scientific hypothesis. More recently, Stanford (2006) has further developed Sklar's insight to defend his instrumentalist view of science. 
demonstrate that only true beliefs may lead us to successfully dealing with the world, ${ }^{7}$ we cannot even eliminate the possibility that an ability in perceiving some falsities as self-evident has been selected, because perceiving such falsities as selfevident truths was adaptively useful (Nozick 2001; see also Vaidya 2016).

It is worth noticing that, if we want to maintain that mathematical knowledge is certain, and we want to naturalize mathematical knowledge, the evolved cognitive ability to grasp whether axioms are consistent, cannot be supposed to be fallible.

Indeed, if this faculty is fallible, and we are not able to correctly determine whether axioms are true in all the cases we examine, then we will be generally unable to claim that our mathematical knowledge is certain in any particular case. Indeed, as we have seen, a mathematical result is true and certain if the axioms from which it is derived are 'true' (in the sense of consistent), and deduction is truth-preserving. If naturalizing mathematics implies that our evolved ability in assessing the truth of the axioms is fallible, and we have no other way to verify our verdict, we find ourselves in a situation in which we may have erred and we are unable to detect whether we erred. Thus, we would be unable to claim that we judged correctly, and so that our mathematical knowledge is certain. So, if the justification of our mathematical knowledge rests on some fallible faculty, then the attempt to naturalize mathematics cannot maintain the traditional view of mathematics. ${ }^{8}$

\section{Mathematics and Naturalism}

As to how to understand 'naturalism', we are not concerned here with any specific view of naturalism, nor we will survey the many criticisms that have been moved to this (family of) view(s) (for a survey, see Clark 2016; Papineau 2016; Rosenberg 1996). For the purpose of this article, 'naturalism' can just be understood as the claim that we should refuse accounts or explanations that appeal to non-natural entities, faculties or events, where 'non-natural' has to be understood as indicating that those entities, faculties or events cannot in principle be investigated, tested and accounted for in the way we usually do in science. In other words, non-natural

7 Cf. McKay, Dennett 2009, 507: "In many cases (perhaps most), beliefs will be adaptive by virtue of their veridicality. The adaptiveness of such beliefs is not independent of their truth or falsity. On the other hand, the adaptiveness [...] of some beliefs is quite independent of their truth or falsity."

8 For an opposite view see McEvoy (2004), who argues for the compatibility of reliabilism and mathematical realism. According to him, mathematical intuition may be at the same time an a priori, reliable, and fallible faculty of reason. In a similar vein, Brown (2012) maintains that Platonism and fallibilism can be combined. But, even if we concede that fallibilism in epistemology is compatible with Platonism in ontology, this view seems not compatible with a naturalist stance, since it is not able to give a naturalist account of how intuition can provide mathematical knowledge that is certain. This view has to face the same difficulties discussed above with regard to the justification of the claim that deduction is truth-preserving: when evolution enters the picture, it is not easy to justify the claim that we are able to correctly assess what is possible or impossible through reasoning alone. This impinges on the possibility of claiming that our mathematical beliefs are certainly true. So, any kind of evolutionary reliabilism seems not really able to provide a naturalist way of supporting the traditional view of mathematics, since it is not able to secure the certainty of our mathematical knowledge (Sage 2004). 
entities, faculties or events are those that are characterized and defined precisely by their inaccessibility, by the impossibility of being assessed, empirically confirmed, or even made compatible with what we consider genuine scientific knowledge in the same or in some close domain of investigation. In all those cases we have to face a problem of access ${ }^{9}$ and a claim of exceptionality that usually lacks sufficiently strong reasons to be conceded.

So, in this article we will exclusively be concerned with those strategies aimed at naturalizing a domain $\mathrm{D}$, which has traditionally been considered to be affected by an 'access problem' (e.g. mathematics, morality, modality, etc.), by providing a plausible evolutionary account of some cognitive abilities that would make our knowledge of some D-truths a natural fact. As an example, consider Timothy Williamson's approach to modality. He firstly reduces the problem of explaining modal knowledge to the problem of explaining our capacity to correctly perform counterfactual reasoning. Then, he gives some reasons to think that an evolutionary account of the emergence of this capacity may be plausible (Williamson 2000).

In this context, a naturalistic account of mathematics has to assume the hypothesis that the human mathematician is "a thoroughly natural being situated in the physical universe," and that therefore "any faculty that the knower has and can invoke in pursuit of knowledge must involve only natural processes amenable to ordinary scientific scrutiny" (Shapiro 1997, 110).

Recently, Helen De Cruz argued that an evolutionary account of mathematics may well be compatible with a realist view of mathematics. According to her, "animals make representations of magnitude in the way they do because they are tracking structural (or other realist) properties of numbers" (De Cruz 2016, 7). In this view, "realism about numbers could be true, given what we know about evolved numerical cognition" (Ibidem, 2). Indeed, "it seems plausible that numerical cognition has an evolved, adaptive function," and it has been

9 See Benacerraf (1973). Benacerraf's famous epistemological challenge to Mathematical Platonism has been criticized because it assumes the causal theory of knowledge, which nowadays is discredited among epistemologists. But Benacerraf's argument may be raised against Platonism without assuming the causal theory of knowledge, as Field maintains (Field 1989). On this issue cf. Baron 2015, 152: "Field's version of the access problem focuses on mathematicians' mathematical beliefs. The mathematical propositions that mathematicians believe tend to be true. If platonism is correct, however, then these propositions are about mathematical objects. So, the mathematical beliefs held by mathematicians [...] are reliably correlated with facts about such objects. The challenge facing the platonist, then, is to provide an account of this reliable correlation." It may be objected that this formulation implicitly assumes the correspondence view of truth, and that this view of truth has not to be necessarily held by platonists. But, even if accepting that view of truth is not strictly mandatory for a realist, the correspondence view is in fact the view of truth usually adopted by realists of all stripes. And according to many authors, one of the major arguments "for mathematical realism appeals to a desire for a uniform semantics for all discourse: mathematical and non-mathematical alike [...]. Mathematical realism, of course, meets this challenge easily, since it explains the truth of mathematical statements in exactly the same way as in other domains" (Colyvan 2015, sec. 5), i.e. by assuming that there is a correspondence between the realm of mathematical objects and our mathematical knowledge. So, if platonists try to avoid Benacerraf's challenge by rejecting the correspondence view of truth, they risk dismissing one of the most convincing reasons for adopting Platonism in the first place. 
demonstrated that numerical cognition "plays a critical role in our ability to engage in formal arithmetic" (De Cruz 2016, 4).

The main problem with this line of reasoning is the following: if we try to naturalize mathematics and maintain the traditional view, i.e. the view according to which the method of mathematics is the axiomatic method and mathematical knowledge is certain, then our naturalized account of mathematics risks to become incompatible with Gödel's results. Indeed, in this view, as we have already noted, in order to justify mathematical knowledge, at least two requirements have to be fulfilled: axioms have to be shown to be consistent, and deduction has to be shown to be truth-preserving.

Let's focus on the first requirement. If we maintain that evolution is able to justify the traditional view of mathematics, this amounts to claim that evolution, in some way, gave us an ability to know with certainty whether axioms are true, at least in the sense that they are consistent. Let's name the 'result' that we obtain thanks to such evolved ability, i.e. "the axioms of the axiomatic system we are considering are consistent", $T$.

The problem is that, by Gödel's second incompleteness theorem, it is impossible to demonstrate in any sufficiently powerful axiomatic system that the axioms of such system are consistent. Let's name this result $G$.

Now, if the method of mathematics really is the axiomatic method, how could we accept that $T$ holds? Or, to put it slightly differently, should we consider $T$ be part of our mathematical knowledge?

If $T$ is part of our mathematical knowledge, then the axiomatic method is not really the unique method of mathematics, since a crucial result as $T$ is not obtained by this method, and so the method by which $T$ has been obtained has to be added to the list of the legitimate methods of mathematics. This would render $G$ almost irrelevant. Indeed, if the axiomatic method is not the only acceptable method in mathematics, and if we can know that a set of axioms is consistent thanks to some evolved faculty, then that in some axiomatic systems we cannot prove whether a set of axioms is consistent is irrelevant to us. The fact that the axioms are consistent could be taken to be established by our evolved faculty.

But the majority of mathematicians, even of platonist mathematicians, would be unwilling to consider Gödel's contributions as irrelevant, and the consistency of axioms establishable by merely relying on an evolved sort of intuition. Precisely because they do believe the axiomatic method to be the method of mathematics, they tend to confer a higher degree of certainty to Gödel's results, which have been established according to such method, than to the intuitions of an evolved faculty, the reliability of which cannot be proved by the same method. Indeed, in a naturalist framework, our evolved intuitions may be shown to be reliable only through some inductive method, which is peculiar of natural science. If we concede that the method of mathematics is distinct from the method of natural science, as the traditional view holds, and that the method of mathematics is the axiomatic method, then we will be unable to sufficiently justify the belief that our evolved intuition is reliable up to a degree which is comparable with the confidence that the axiomatic method is supposed to confer to mathematical results. Thus, even if our evolved intuition were in fact reliable and infallible, we would be unable to demonstrate its infallibility with the same degree of certainty with which Gödel's results can be proven, given that they are mathematical results.

If, on the other hand, we take $T$ not to be part of our mathematical knowledge, and protest that $T$ is not really a 'mathematical result', we will nevertheless find 
ourselves in an uncomfortable position: we should maintain that we possess some knowledge about some mathematical issue which is not part of our mathematical knowledge. It is not easy to accommodate this claim by the usual epistemological standards. Since knowledge requires (at least) truth and justification, if we take $T$ to be knowledge, $T$ is true and justified. If $T$ expresses something true about some mathematical issue, then we can affirm that $T$ expresses a mathematical truth. But if we refuse to consider $T$ as a part of our mathematical knowledge, and we are not able to express the same mathematical truth that $T$ expresses by the means of what we take to constitute our current mathematical knowledge, then $T$ would be able to express a mathematical truth that our mathematical knowledge would be unable to express.

It may be objected that $T$ expresses a mathematical truth that cannot be expressed on the basis of our mathematical knowledge, because the justification requirement that a true belief needs to fulfill in order to become mathematical knowledge is stricter than the justification requirement that has to be fulfilled in other domains. Let's concede, for argument's sake at least, such claim on the justification requirement for mathematics. ${ }^{10}$ If this is the case, $T$ could well be able to express a truth about some mathematical issue, but this truth may nevertheless be insufficiently justified in order to become part of our mathematical knowledge. And this would explain the fact that $T$ is able to express a truth on a mathematical issue, and that this truth does not figure among our known mathematical truths. But this would amount saying that our mathematical knowledge is a kind of knowledge with a higher degree of certainty than $T$, since the true beliefs that constitute our mathematical knowledge are supposed to display a higher degree of justification.

But if we try to naturalize mathematics in the way here we are dealing with, things should go the other way round. Since $T$, in order to be able to justify the traditional view of mathematics has to be certain, $T$ has to be knowledge with the highest degree of certainty. Thus, the degree of certainty that our mathematical knowledge may display is in some sense subordinated to $T$, since its certainty is dependent on the certainty of $T$. Mathematical knowledge would be in this way a kind of knowledge with a less high degree of certainty than $T$. Thus, it cannot be the case that the mathematical truth expressed by $T$ is not an instance of mathematical knowledge because it is insufficiently justified. So, this objection is inadequate.

Since in both cases, i.e. either we take $T$ to be part of mathematical knowledge or not, we end with implausible scenarios, the supporters of the traditional view seem unable to really find an adequate way of naturalistically justifying the claim that mathematics is the paradigm of certain knowledge.

\section{The Analytic Method}

We will now present the analytic view of method in some detail and try to underline the reasons why it may be of use to those interested in the attempt of naturalizing mathematics. There are three main claims that characterize the analytic

10 Cf. e.g. Kitcher 1988, 297: "The obvious way to distinguish mathematical knowledge from mere true belief is to suggest that a person only knows a mathematical statement when that person has evidence for the truth of the statement-typically, though not invariably, what mathematicians count as a proof." 
view of method: 1) the method of mathematics is the analytic method, and not the axiomatic method; 2) the concept of truth proved to be inadequate to account for the method of mathematics, natural sciences, and philosophy, and thus has to be replaced with the concept of 'plausibility'; 3) since mathematics, natural sciences, and philosophy all aim at acquiring new knowledge, they all share the very same method, i.e. the analytic method, which is the method through which knowledge can be ampliated.

Let's start with 1), the claim that the analytic method is the method of mathematics. The analytic method may be defined as the method according to which:

to solve a problem, one looks for some hypothesis that is a sufficient condition for solving it. The hypothesis is obtained from the problem, and possibly other data already available, by some non-deductive rule, and must be plausible [...]. But the hypothesis is in its turn a problem that must be solved, and is solved in the same way [...]. And so on, ad infinitum. Thus solving a problem is a potentially infinite process (Cellucci 2013, 55).

The origin of the analytic method may be traced back to the works of the mathematician Hippocrates of Chios and the physician Hippocrates of Cos, and was firstly explicitly formulated by Plato in Meno, Phaedo and the Republic. As an example of the analytic method, consider the solution to the problem of the quadrature of certain lunules provided by Hippocrates of Chios:

Show that, if $P Q R$ is a right isosceles triangle and $P R Q, P T R$ are semicircles on $P Q, P R$, respectively, then the lunule $P T R U$ is equal to the right isosceles triangle $P R S$.

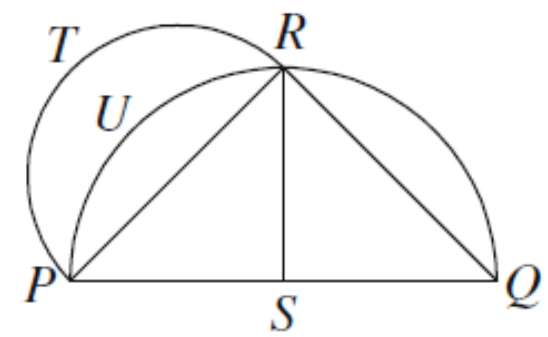

To solve this problem, Hippocrates of Chios states the following hypothesis:

(B) Circles are as the squares on their diameters.

Hypothesis (B) is a sufficient condition for solving the problem. For, by the Pythagorean theorem, the square on $P Q$ is twice the square on $P R$. Then, by (B), the semicircle on $P Q$, that is, $P R Q$, is twice the semicircle on $P R$, that is, $P T R$, and hence the quarter of circle $P R S$ is equal to the semicircle $P T R$. Subtracting the same circular segment, $P U R$, from both the quarter of circle $P R S$ and the semicircle PTR, we obtain the lunule $P T R U$ and the triangle $P R S$, respectively. Therefore, "the lunule" $P T R U$ "is equal to the triangle." [Simplicius, In Aristotelis Physicorum libros Commentaria, A 2, 61]. This solves the problem. But hypothesis (B) is in its turn a problem that must be solved. (Cellucci 2013, 61). 
And in fact, this new problem was solved, presumably by Eudoxus, proposing the following hypothesis: (B') Similar regular polygons inscribed in circles are as the squares on their diameters. Hypothesis (B') is a sufficient condition for solving the problem, i.e. hypothesis (B), but hypothesis (B') is in its turn a problem that must be solved. And so on, ad infinitum.

The analytic method is the method that from antiquity has been used to advance mathematical knowledge, to acquire new knowledge. On the contrary, the axiomatic method has been developed, and was probably already used by mathematicians at Plato's time, mainly as a didactic tool, in order to teach already acquired knowledge:

\begin{abstract}
Aristotle states that, in order to present, justify, and teach an already acquired proposition, we must start from the principles proper to the subject matter of the proposition, and deduce the proposition from them, since "didactic arguments are those that deduce" propositions "from the principles proper to each subject matter" (Aristotle, De Sophisticis Elenchis, 2, 165 b 1-2). (Cellucci forthcoming, sec. 12.9).
\end{abstract}

According to Aristotle, who firstly explicitly formulated the axiomatic method in Posterior Analytics, the "mathematical sciences are learned in this way, and so is each of the other arts" (Aristotle, Analytica Posteriora, A 1, 71 a 3-4). The merely didactic nature of the axiomatic method clearly emerges from the fact that Aristotle distinguishes between the analytic-synthetic method, which according to him is the method of research, and the axiomatic method, which is the method to present results already acquired.

In the last century, the dominance of a foundationalist perspective on scientific and mathematical knowledge, the influence of Hilbert's thought, and the diffusion of the idea that a logic of discovery cannot exist, led to the widespread conviction that the method of mathematics and science is (or should be) the axiomatic method, ${ }^{11}$ according to which, to demonstrate a statement, one starts from some given premises, which are supposed to be true, and deduces the statement from them. Analysis has been overlooked or neglected (Schickore 2014; Cellucci 2013).

For example, the hypothetico-deductive model of science, which is still dominant although it has been severely criticized, ${ }^{12}$ is based on the axiomatic method. According to the hypothetico-deductive view of science, building "a scientific theory is a matter of choosing certain hypotheses, deducing consequences from them, and comparing consequences with the observation data" (Cellucci forthcoming, sec. 13.5). In this perspective, the process of knowledge ampliation is accounted for in terms of deductive reasoning. The problem is that the "propositions deduced from the hypotheses contain nothing essentially new with respect to the hypotheses," because deduction is non-ampliative, "it simply makes explicit what is implicitly contained in the hypotheses" (Ibidem, sec. 13.6). ${ }^{13}$

11 For a historical survey of the main conceptions of scientific and mathematical method that have been put forward so far, see Cellucci $(2016,2013)$. On the analytic method, see also Hintikka, Remes (1974), and Lakatos (1978), vol. 2, chap. 5. On Plato's formulation of the analytic method, see Menn (2002). For a historical survey of the axiomatic method, and the relevance of Hilbert's view, see Rodin (2014), part I.

12 See Schickore (2014) for a survey.

13 The characterization of deduction as non-ampliative has been questioned, e.g., by Haack (1996). For a rejoinder, see Cellucci (2006). 
Thus, the axiomatic method may illustrate how to derive a result from certain premises, but it does not explain how we got there. This is the reason why, according to the analytic view of method, the axiomatic method is inadequate to support a naturalist perspective on mathematics and science. Indeed, the axiomatic method does not account for the process of hypotheses production, and so it is not able to show the path that mathematicians and scientists follow to reach a result and solve a problem. Thus, the axiomatic method cannot improve our understanding of how we produce knowledge. From a naturalist perspective, it is unsatisfying that the alleged method of mathematics is unable to say anything relevant on how mathematical knowledge is acquired. If knowledge ampliation remains a mystery, naturalists cannot adequately counter those anti-naturalists who maintain that it is necessary to take into consideration some non-natural element in order to explain our ability to produce mathematical knowledge.

On the contrary, in the analytic view the path that has been followed to reach a result and solve a problem is not occulted, since in this view the context of discovery is not divorced from the context of justification. Indeed, an analytic demonstration consists in a non-deductive derivation of a hypothesis from a problem and possibly other data, where the hypothesis is a sufficient condition for the solution of the problem, and is plausible (Ibidem, chap. 21).

It is important to underline that the analytic method involves both deductive and non-deductive reasoning. Indeed, to find a hypothesis we proceed from the problem in an ampliative (i.e. non-deductive) way performing ampliative inferences, and then in order to assess the plausibility of such hypothesis we deduce conclusions from it. But the role that deduction plays in the analytic view is not the crucial role that deduction is supposed to play in the 'received view', i.e. the axiomatic method, which can be considered as a variant of the analyticsynthetic method. According to the analytic view, axioms are not the source of mathematical knowledge, and we shouldn't overestimate their role, which is limited to giving us the possibility of presenting, for didactic or rhetorical purposes,${ }^{14}$ some body of already acquired knowledge in deductive form. Axioms do not enjoy any temporal or conceptual priority in the development of mathematical knowledge, nor they play any special epistemological role. As Hamming states, if "the Pythagorean theorem were found to not follow from postulates, we would again search for a way to alter the postulates until it was true. Euclid's postulates came from the Pythagorean theorem, not the other way" (Hamming 1980, 87).

In order to avoid misunderstanding, it has to be underlined that the analytic method has not to be confused with the analytic-synthetic method. Indeed, it may be objected that when we stop, since it seems that we have to, the place where we stop can be regarded as an 'axiom', and so we are back in the axiomatic method. But it is not so. This objection derives precisely from confusing the analytic method with the analytic-synthetic method. According to the analytic-synthetic method, as stated by Aristotle, the search for a solution to a problem is a finite process, "so the ascending sequence of the premises must terminate," and once the

14 Cf. Cellucci forthcoming, sec. 22.7: "the purpose of axiomatic demonstration is to justify and teach an already acquired proposition. This serves to convince the audience - readers of research papers or textbooks, conference audiences or students in the classroom - that the proposition should be accepted. Therefore, several people have asserted that axiomatic demonstration has a rhetorical role." 
prime premises have been found, "the only role which remains for analysis is to find deductions of given conclusions from prime premises," therefore the analyticsynthetic method "is primarily a method [...] for finding demonstrations in given axiomatic systems" (Cellucci 2013, 75). In this view, once the process of discovery ends, there is no more a relevant role for the analytic method.

On the contrary, according to the analytic method, the process of discovery is a potentially infinite process. So, since the process of discovery never really ends, there is no relevant role for the axiomatic method in this view. Indeed, even if we provisionally stop, we know that we will have to go further in order solve the problem of justifying the hypothesis where we stopped. ${ }^{15}$

\subsection{Plausibility in Place of Truth}

Let's examine the second qualifying claim of the analytic view, which states that we should replace the concept of truth with the concept of 'plausibility' (see above, sec. 4). The ('Kantian') reasons for adopting plausibility in place of truth in order to account for human knowledge, may be briefly summarized as follows: since the main definitions of truth that have been proposed so far proved unable to give us a workable criterion of truth, i.e. a nonalgorithmic means to decide whether a given statement is true, they cannot avoid the sceptical argument of the criterion (see Cellucci 2014a). ${ }^{16}$ In other words, if we maintain that knowledge requires truth, and adopt one of the traditional definitions of truth, since our conception of truth cannot face the sceptical challenge of the criterion, we would never be able to assess whether we really reached some truth, and so whether our knowledge is genuine knowledge. So, if knowledge requires truth, knowledge is epistemically unattainable by humans. But if knowledge is epistemically unattainable, we will never be able to account for our having knowledge, let alone to account for our having knowledge naturalistically. Since truth is such an unrealistic aim for our human epistemic activities, we should instead take plausibility to be the central concept of epistemology: ${ }^{17}$

15 It may be objected that, if solving a problem is a potentially infinite process, we could be unable to assess whether we were really able to solve a given problem or not. This objection seems to rest on the idea that a genuine solution to a given problem has to be a definite solution, i.e. a solution that will never be altered, or overcome by a better solution. In this view, once a problem is solved, we should not keep trying to solve it. But there is no compelling reason why a solution to a problem should not be thought to be a genuine solution, unless it can be proved that it is a definite solution. Think to mathematics. In mathematics, solutions are routinely searched also for those problems for which a solution has already been found. And solutions that once were regarded as adequate, have often successively been regarded as inadequate. As Poincaré states, in mathematics there are not "solved problems and others which are not; there are only problems more or less solved," where "it often happens however that an imperfect solution guides us toward a better one" (Poincaré 2015, 377-378).

16 The problem of the criterion of truth is the ancient sceptical paradox of the wheel: "in order to know any proposition we must first know a criterion, but in order to know a criterion we must already know some proposition" (Cling 1997, 109). For a survey, see Amico (1993).

17 This argument can be called 'Kantian', since it is analogous to the 'Kantian' argument against metaphysical realism. David summarizes this argument as follows: "We cannot 
the goal of science is plausibility. Scientific theories do not deal with the essence of natural substances, but only with some of their phenomenal properties, and deal with them on the basis of plausible hypotheses. Then a scientific theory is not a set of truths but rather a set of plausible hypotheses. Thus the goal of science is plausibility rather than truth (Cellucci 2013, 154).

But how should we conceive of plausibility? The plausibility of a hypothesis is assessed by a careful examination of the arguments for and against it. According to Cellucci, in order to judge over the plausibility of a hypothesis, the following 'plausibility test procedure' has to be performed:

(1) Deduce conclusions from the hypothesis.

(2) Compare the conclusions with each other, in order to see that the hypothesis does not lead to contradictions.

(3) Compare the conclusions with other hypotheses already known to be plausible, and with results of observations or experiments, in order to see that the arguments for the hypothesis are stronger than those against it on the basis of experience (Ibidem, 56).

If a hypothesis passes the plausibility test procedure, it can be temporarily accepted. If, on the contrary, a hypothesis does not pass the plausibility test, it is put on a 'waiting list', since new data may emerge, and a discarded hypothesis may successively be re-evaluated.

Thus, according to the analytic view of method, what in ultimate analysis we really do, and are able to do, in the process of knowledge ampliation, is nondeductively producing hypotheses, assessing the arguments for and the arguments against each hypothesis, and provisionally accept or refuse such hypotheses. ${ }^{18}$

\subsection{The Analytic Method and The Biological Role of Knowledge}

step outside our own minds to compare our thoughts with mind-independent reality. Yet, on the realist correspondence view of truth, this is what we would have to do to gain knowledge of the world. We would have to access reality as it is in itself, to determine whether our thoughts correspond to it. Since all our access to the world is mediated by our cognition, this is impossible. Hence, on realism, knowledge of the world would be impossible. Since knowledge of the world is possible, realism must be wrong" (David 2016, 173).

18 This conception of 'plausible hypotheses' is similar, but not identical, to Aristotle's definition of endoxa. Cf. Cellucci forthcoming, sec. 9.5: "endoxa are things which seem acceptable to everyone, or to the great majority, or to the wise, etc., on the basis of an examination of the arguments for and against them, from which the former turn out to be stronger than the latter. [...]. However, that plausibility is to a certain extent related to Aristotle's endoxa does not mean that plausibility and endoxa are identical. For Aristotle, endoxa are continuous with truth. Indeed, he states that 'an ability to aim at endoxa is a characteristic of one who also has a similar ability in regard to the truth'. (Aristotle, Rhetorica, 1355 a 17-18). Conversely, plausibility [...] is an alternative to truth. Therefore, plausibility and endoxa are not identical." 
To better understand the third qualifying claim of the analytic view listed above (sec. 4), according to which mathematics, natural sciences, and philosophy share the same method, i.e. the analytic method, we have to focus on the biological role of knowledge. In this view, the main consequence of considering the biological role of knowledge is that knowledge cannot be related to the concept of truth. ${ }^{19}$ Indeed, if knowledge is related to our biological make-up, and the latter is related to evolution, then in order to account for what knowledge is, it is better to abandon the concept of truth for at least three reasons, which can be briefly described as follows: 1) evolution is not an aimed-at-truth process, or, at least, the claim that natural selection leads to truth is so debated and controversial that it cannot represent a firm ground on which one can develop a satisfying account of knowledge $;{ }^{20} 2$ ) if knowledge is something that biological entities produce in order to deal with their environment, then it cannot be independent from the subject's biological make-up. Thus, if truth has to be intended, as many realists say, as a non-epistemic concept, i.e. as unrelated to the subject who knows, then human knowledge cannot be related to truth ${ }^{21} 3$ ) if knowledge is related to truth, and truth is not attainable by humans, because its epistemic standard is so elevated that cannot be met by humans, then knowledge would be impossible. Since knowledge is not only possible, but it is necessary for the survival, knowledge cannot be related to truth (Cellucci 2013). For those reasons, the analytic view considers 'truth' an unuseful concept in order to naturalistically account for knowledge, i.e. to see knowledge as a human activity that is made possible by our evolved abilities and which is indispensable for the survival.

A brief clarification is in order. Since the reference to the concept of truth is usually seen as a characterizing feature of realism, someone may deem the analytic view an 'antirealist' position. Obviously, it is undeniable that the analytic view gives up any reference to the notion of 'truth'. But the analytic view must not be confused with other views, which can be regarded, broadly speaking, as 'antirealists'. For instance, the analytic view has not to be confused with idealism. Indeed, the analytic view does not deny the existence, nor the independence of the external reality. It is not a form of metaphysical antirealism. Nor should the analytic view be confused with scepticism. Indeed, the analytic view does not deny the possibility of knowledge. It claims that knowledge is possible and that we do have knowledge, but it denies that knowledge needs to be true, simply because it denies that the concept of truth is necessary to define knowledge.

Turning to the issue at stake, as already noted, the analytic view considers knowledge to be necessary for the survival. Now, since "in order to survive, all organisms must acquire knowledge about the environment," this means that "knowledge is a natural phenomenon that occurs in all organisms" (Cellucci 2013, 250). Since knowledge is necessary for the survival, and the analytic view sees knowledge as the result of solving problems by the analytic method, this means that knowledge is essentially a problem-solving process that is homogeneous throughout the biological realm.

19 This is one of the main differences between the analytic view and the attempts aimed at naturalizing knowledge made by Kornblith (2002) and Plotkin (1997), since both Kornblith and Plotkin maintain that knowledge is related to truth.

20 On the difficulty of supporting the claim that evolution leads to truth, see Sage (2004).

21 Cf. Sankey 2008, 112: "The realist conception of truth is a non-epistemic conception of truth, which enforces a sharp divide between truth and rational justification." 
Moving along this line, the analytic view supports the naturalist claim that mathematics, philosophy and science are continuous. Indeed, mathematics, philosophy and science are human attempts to acquire knowledge, knowledge is essentially problem solving, and problems are solved throughout the biological realm by the analytic method. So, mathematics, philosophy and science are continuous because their method is the very same method. ${ }^{22}$ Moreover, in this perspective, mathematics, philosophy and science may be accounted for in naturalistic terms, because they solve human problems in the same way in which problems are solved in the rest of the biological realm, i.e. through the analytic method.

\subsection{The Analytic Method and Fallibilism}

As we have seen, the analytic view of method takes knowledge acquisition to be a potentially infinite process, and knowledge to be always hypothetical and provisional:

Solving problems by the analytic method, when successful, produces knowledge, though knowledge that, being based on hypotheses that are only plausible, is not absolutely certain. [...] there is a strict connection between knowledge and the analytic method: knowledge arises from solving problems by the analytic method. (Cellucci 2015, 224-225).

Since the analytic method is the method of mathematics, this means that according to this view, mathematical knowledge cannot be said to be certain. And that the only mathematical knowledge we can have is knowledge which is plausible. This view may certainly appear prima facie extremely revisionary with respect to traditional epistemology and philosophy of mathematics. But it nevertheless displays some vantages, the most important of which is that it is compatible with both our current mathematical and scientific knowledge.

Indeed, the claim that mathematical knowledge is plausible is compatible with Gödel's results. A proposition cannot be more justified than the axioms from which it is deduced, and, by Gödel's second incompleteness theorem, no absolutely reliable justification for the axioms is generally possible. Thus, if we claim that our mathematical knowledge is certain, while the axioms from which this mathematical knowledge is derived cannot be justified up to certainty, this claim would be incompatible with an established mathematical result. While, if we claim, following the analytic view, that our mathematical knowledge is plausible, this claim is not in contrast with any established mathematical result, since axioms as well as the propositions that we deduce from them may safely be deemed to be plausible.

Moreover, that mathematical knowledge is plausible is also compatible with our current scientific knowledge, according to which there is no evidence that we humans possess such a special cognitive faculty as the 'intuition' that we should assume to possess in order to guarantee that the axioms from which we derive our mathematical knowledge are true. Thus, if we claim that mathematical knowledge is certain, and there is no mathematical way to justify up to certainty the axioms

22 On the difference between science and philosophy, see Cellucci (2014b). On the method of science and the 'models of science', see also Cellucci (2016). 
from which we derive our mathematical theories, then we have to subscribe to the view according to which we can say that our axioms are true because our 'intuition' is in some way able to know that they are true with certainty. Now, there are no cues that such 'intuition' may exist, nor any scientifically plausible account of how exactly it may work has been provided, nor any plausible account of how it could have evolved has been provided. On the opposite, cognitive science and evolutionary biology give us good reasons to think that such a faculty does not exist, and that perhaps it cannot even exist. So, if we claim that mathematical knowledge is certain, this claim is incompatible with our current scientific knowledge. While, if we claim, following the analytic view, that our mathematical knowledge is plausible, this claim is not incompatible with our current scientific knowledge, since in order to claim for the plausibility of our mathematical knowledge there is no need to postulate the existence of any extravagant faculty.

From what we have seen, it is clear that the analytic view may be deemed, broadly speaking, a fallibilist epistemological approach. Therefore, it may be worth briefly stressing some of the differences that exist between the analytic view and other fallibilist perspectives, namely 'Popperian' and 'Lakatosian' approaches, which certainly have been very influential in the development of the analytic view.

First of all, the analytic view shares with Popper the idea that knowledge is essentially problem solving, but, unlike Popper, it does not separate the context of discovery from that of justification, nor it denies the relevance of the context of discovery. And being especially focused on the context of discovery makes the analytic view well suited to figure as a component of a naturalist account of the process of knowledge ampliation, because it does not make of this crucial aspect of knowledge acquisition a mystery. ${ }^{23}$

Secondly, according to the analytic view, in order to solve problems, hypotheses are produced by non-deductive inferences, so logic is essentially a logic of discovery. Thus, in this perspective, contrary to Popper's view, logic has not to be intended as a merely deductive enterprise, and the non-deductive ampliative rules are considered to be legitimate parts of logic as well as the deductive and non-ampliative ones. ${ }^{24}$ Indeed, the analytic method "is a logical method" and from the fact that "knowledge is the result of solving problems by the analytic method, it follows that logic provides means to acquire knowledge" (Cellucci 2013, 284).

It is worth noticing that claiming that the analytic method is a logic of discovery does not mean to deny the relevance of unconscious processes in scientific discovery. Indeed, "in the analytic method, some non-deductive inferences by which hypotheses are obtained may be unconscious" (Ibidem, 235). So, according to the analytic view, unconsciously formulated hypotheses should not be considered irrational. Moreover, the analytic view denies that a logic of discovery cannot exist because the processes involved in the discovery are purely subjective and psychological. Indeed, in this view, the non-deductive rules by which the

23 Cf. e.g. Lakatos 1978, vol. 1, 140: "for Popper the logic of discovery [...] consists merely of a set of [...] rules for the appraisal of ready articulated theories."

24 On the fact that, since there is no non-circular justification of the validity of deductive inferences rules, nor there is an adequate justification of the acceptability of circular justifications, non-deductive rules and deductive rules are on a par with respect to the issue of the justification of their validity, see Cellucci (2006). See also Haack (1976), and Carroll (1895). 
analytic method "is implemented [...] are as objective as the deductive rules of a logic of justification" (Ibidem, 289).

Coming to 'Lakatosian' approaches, although these approaches and the analytic view both stress the role of heuristic in the ampliation of knowledge and strongly criticize the axiomatic view, ${ }^{25}$ they are distinct positions. The main difference between those positions can probably be identified by analyzing their views on the issue of truth: while Lakatos maintains that the aim of science is truth, and truth is correspondence ${ }^{26}$ the analytic view replaces truth with plausibility for the reasons outlined above. ${ }^{27}$

\subsection{The Analytic Method and Infinitism}

The analytic view aims at avoiding both a) scepticism, since, as we have already stressed above, it takes knowledge not only to be possible, but even necessary to the survival, and b) foundationalism, given that it takes knowledge to be a potentially infinite process. To better clarify this point, it may be useful to point out some of the differences between the analytic view and infinitism, an epistemological position that is usually credited by its supporters to be similarly able to avoid both scepticism and foundationalism (Turri, Klein 2014).

The analytic view and infinitism agree that the fact that knowledge acquisition may be a potential infinite process does not prevent us to consider genuine knowledge the portion of knowledge we reached so far. Nevertheless, they are distinct positions. Infinitism usually retains the relation between the concept of knowledge and the concept of truth, and thus have to face several difficulties. For example, Cling (2004) underlines that if knowledge has to be related to truth, it is not sufficient to consider infinite patterns of reasons as acceptable in order to claim that we have knowledge, we should also be able to distinguish those infinite patterns that allow us to reach the truth from those which don't. But to do that, we should be able to identify some properties which characterize true reasons. This would amount to already have a criterion of truth, and would undermine the infinitist attempt to avoid the challenge of the criterion of truth exactly by allowing the infinite regress of reasons. Thus, infinitism per se seems unable to solve the sceptical problem of the criterion and the related problem of the infinite regress.

On the contrary, the analytic view can safely maintain that knowledge acquisition is a potentially infinite process and that the portion of knowledge we have produced so far is genuine knowledge, since the analytic view conceives of knowledge as plausible and provisional:

if the series of the premisses is infinite, there will be no immediately justified premisses, so no knowledge will be definitive. But this does not mean that there will be no knowledge. There would be no knowledge only if the premisses, or hypotheses, occurring in the infinite series were arbitrary. But

25 Lakatos is considered to be the initiator of the 'maverick' tradition in the philosophy of mathematics (Kitcher, Aspray 1988, 17). Relying on the work of Pólya, he strongly criticized the occultation of the heuristic elements that proved crucial in developing mathematics. See Lakatos (1976).

26 See Lakatos (1978).

27 There are several other differences between Lakatos' and Cellucci's view of heuristic which cannot be discussed here for reason of space. See Cellucci (forthcoming, 2013). 
they need not be arbitrary [...] they must be plausible, namely the arguments for them must be stronger than the arguments against them, on the basis of the existing knowledge. If the hypotheses are plausible, then there will be knowledge, albeit provisional knowledge [...] since new data may always emerge. (Cellucci forthcoming, sec. 3.2).

It is worth underlining here that 'plausibility' has not to be confused with 'probability'. Indeed, as Kant points out, "plausibility is concerned with whether, in the cognition, there are more grounds for the thing than against it" (Kant 1992, 331), while probability measures the relation between the winning cases and possible cases. Plausibility involves a comparison between the arguments for and the arguments against, so it is not a mathematical concept. Conversely, probability is a mathematical concept.

\section{Conclusion}

This article tried to suggest that, since it seems that the traditional view of mathematics cannot be naturalized, if we wish to maintain a naturalist stance, a promising way to account for mathematics and mathematical knowledge may be to take the method of mathematics to be the analytic method.

It has been argued that it is impossible to naturalize mathematics without challenging at least some crucial aspects of the traditional view. Nor it seems possible to keep maintaining that the method of mathematics is the axiomatic method and mathematical knowledge is certain, if we dismiss that view.

The analytic view has been illustrated in some detail. To make the proposal of taking the method of mathematics, natural science, and philosophy to be the analytic method more intelligible, the differences between the analytic view and some related epistemological positions have been pointed out.

Certainly, the analytic view comes with a cost: it forces us to rethink the 'traditional image' of mathematics. Indeed, if we take the method of mathematics to be the analytic method, mathematical knowledge cannot be said to be certain, and the only kind of mathematical knowledge that we can have is knowledge which is plausible. But also the alternative option of maintaining the traditional view comes with a cost for the naturalist: she is unable to scientifically account for mathematics, while she maintains the primacy of a thorough mathematized science in her world view. We think that the analytic view may represent a promising route to take for the naturalist, and we tried to show that it is worth of further investigations.

\section{References}

Amico, R.P. (1993). The Problem of the Criterion. Lanham, MD: Rowman \& Littlefield.

Auslander, J. (2008). On the Roles of Proof in Mathematics. In: Gold, B., Simons, R. (eds.), Proof and Other Dilemmas: Mathematics and Philosophy. Washington: The Mathematical Association of America: 62-77.

Baker, A. (2016). Non-Deductive Methods in Mathematics. In: Zalta, E.N. (ed.), The Stanford Encyclopedia of Philosophy, URL = <https://plato.stanford.edu/archives/win2016/entries/mathematics-nondeductive/>. 
Balaguer, M. (2009). Realism and Anti-Realism in Mathematics. In: Gabbay, D., Thagard, P., Woods, J. (eds.) Handbook of the Philosophy of Science. Volume 4. Amsterdam: Elsevier: 117-151.

Baron, S. (2015). Mathematical Explanation and Epistemology: Please Mind the Gap. Ratio, 29: 14-167.

Benacerraf, P. (1973). Mathematical Truth. The Journal of Philosophy, 70: 661-679.

Brown, J.R. (2012). Platonism, Naturalism, and Mathematical Knowledge. New York: Routledge.

Byers, W. (2007). How Mathematicians Think. Princeton: Princeton University Press.

Carroll, L. (1895). What the Tortoise Said to Achilles. Mind, 4: 278-280.

Cellucci, C. (2006). The Question Hume Didn't Ask: Why Should We Accept Deductive Inferences? In: Cellucci, C., Pecere, P. (eds.), Demonstrative and Non-Demonstrative Reasoning. Cassino: Edizioni dell'Università degli Studi di Cassino: 207-235.

Cellucci, C. (2013). Rethinking Logic. Logic in Relation to Mathematics, Evolution, and Method. Dordrecht: Springer.

Cellucci, C. (2014a). Knowledge, Truth and Plausibility. Axiomathes, 24: 517-532.

Cellucci, C. (2014b). Rethinking Philosophy. Philosophia, 42: 271-288.

Cellucci, C. (2015). Rethinking Knowledge. Metaphilosophy, 46: 213-234.

Cellucci, C. (2016). Models of Science and Models in Science. In: Ippoliti, E., Sterpetti, F., Nickles, T. (eds.), Models and Inferences in Science. Cham: Springer: 95-122.

Cellucci, C. (2017). Is Mathematics Problem Solving or Theorem Proving? Foundations of Science, 22: 183-199.

Cellucci, C. (forthcoming). Rethinking Knowledge. The Heuristic View. Dordrecht: Springer.

Clark, K.J. (2016). Naturalism and its Discontents. In: Clark, K.J. (ed.), The Blackwell Companion to Naturalism. Oxford: Blackwell: 1-15.

Cling, A.D. (1997). Epistemic Levels and the Problem of the Criterion. Philosophical Studies, 88: 109-140.

Cling, A.D. (2004). The Trouble with Infinitism. Synthese, 138: 101-123.

Cohen Kadosh, R., Dowker, A. (eds.) (2015). The Oxford Handbook of Numerical Cognition. Oxford: Oxford University Press.

Colyvan, M. (2015). Indispensability Arguments in the Philosophy of Mathematics. In: Zalta, E.N. (ed.), The Stanford Encyclopedia of Philosophy, URL = $<$ https://plato.stanford.edu/archives/spr2015/entries/mathphil-indis/>.

David, M. (2016). Anti-Realism. Disputatio, 8: 173-185.

De Cruz, H. (2006). Towards a Darwinian Approach to Mathematics. Foundations of Science, 11: 157-196.

De Cruz, H. (2016). Numerical Cognition and Mathematical Realism. Philosophers' Imprint, 16: 1-13.

Dehaene, S., Brannon, E.M. (eds.) (2011). Space, Time and Number in the Brain. Amsterdam: Elsevier.

Dehaene, S., Duhamel, J.-R., Hauser, M.D., Rizzolatti, G. (eds.) (2005). From Monkey Brain to Human Brain. Cambridge (MA): MIT Press.

Detlefsen, M. (2011). Discovery, Invention and Realism: Gödel and Others on the Reality of Concepts. In: Polkinghorne, J. (ed.), Meaning in Mathematics. Oxford: Oxford University Press: 73-94.

Deutsch, D. (1997). The Fabric of Reality. New York: Penguin Books.

Feferman, S. (1998). In the Light of Logic. Oxford: Oxford University Press.

Field, H. (1989). Realism, Mathematics and Modality. Oxford: Blackwell.

Franks, J. (1989). Review of J. Gleick, Chaos: Making a New Science. The Mathematical Intelligencer, 11: 65-69.

Frege, G. (1984). Collected Papers on Mathematics, Logic, and Philosophy. Oxford: Blackwell.

George, A., Velleman, D.J. (2002). Philosophies of Mathematics. Malden: Blackwell. 
Gödel, K. (1947). What is Cantor's Continuum Problem? In: Idem (1990), Kurt Gödel. Collected Works. Volume II. Oxford: Oxford University Press: 176-187.

Gödel, K. (1951). Some Basic Theorems on the Foundations of Mathematics and their Implications. In: Idem (1995), Kurt Gödel. Collected Works. Volume III. Oxford: Oxford University Press: 304-323.

Gowers, T. (2006). Does Mathematics Need a Philosophy? In: Hersh, R. (ed.), 18 Unconventional Essays on the Nature of Mathematics. New York: Springer: 182-200.

Haack, S. (1976). The Justification of Deduction. Mind, 85: 112-119.

Haack, S. (1996). Deviant Logic, Fuzzy Logic. Chicago: The University of Chicago Press.

Hamming, R.W. (1980). The Unreasonable Effectiveness of Mathematics. The American Mathematical Monthly, 87: 81-90.

Hintikka, J., Remes, U. (1974). The Method of Analysis. Dordrecht: Reidel.

Horsten, L. (2015). Philosophy of Mathematics. In: Zalta, E.N. (ed.), The Stanford Philosophy,

URL

<http://plato.stanford.edu/archives/spr2015/entries/philosophy-mathematics/>.

Kant, I. (1992). Lectures on Logic. Cambridge: Cambridge University Press.

Kitcher, P. (1988). Mathematical Naturalism. In: Aspray, W., Kitcher, P. (eds.), Minnesota Studies in the Philosophy of Science. Volume XI. Minneapolis: University of Minnesota Press: 293-325.

Kitcher, P., Aspray, W. (1988). An Opinionated Introduction. In: Aspray, W., Kitcher, P. (eds.), Minnesota Studies in the Philosophy of Science. Volume XI. Minneapolis: University of Minnesota Press: 3-57.

Kornblith, H. (2002). Knowledge and its Place in Nature. Oxford: Oxford University Press.

Krebs, N. (2011). Our Best Shot at Truth: Why Humans Evolved Mathematical Abilities. In: Frey, U.J., Störmer, C., Willführ, K.P. (eds.), Essential Building Blocks of Human Nature. Dordrecht: Springer: 123-141.

Kyburg, H. (1965). Comments on Salmon's 'Inductive Evidence'. American Philosophical Quarterly. 2: 274-276.

Lakatos, I. (1976). Proofs and Refutations. Cambridge: Cambridge University Press.

Lakatos, I. (1978). Philosophical Papers. 2 vol. Cambridge: Cambridge University Press.

Leng, M. (2007). Introduction. In: Leng, M., Paseau, A., Potter, M. (eds.), Mathematical Knowledge. Oxford: Oxford University Press: 1-15.

McEvoy, M. (2004). Is Reliabilism Compatible with Mathematical Knowledge? The Philosophical Forum, 35: 423-437.

McKay, R.T., Dennett, D.C. (2009). The Evolution of Misbelief. Behavioral and Brain Sciences, 32: 493-510.

Menn, S. (2002). Plato and the Method of Analysis. Phronesis, 47: 193-223.

Nozick, R. (2001). Invariances. Cambridge (MA): Harvard University Press.

Núñez, R. (2008). Mathematics, the Ultimate Challenge to Embodiment: Truth and the Grounding of Axiomatic Systems. In Calvo, P., Gomila, T. (eds.), Handbook of Cognitive Science: An Embodied Approach. Amsterdam: Elsevier: 333-353.

Núñez, R. (2009). Numbers and Arithmetic: Neither Hardwired Nor Out There. Biological Theory, 4: 68-83.

Papineau, D., (2016). Naturalism. In: Zalta, E.N. (ed.), The Stanford Encyclopedia of Philosophy, URL: <https://plato.stanford.edu/archives/win2016/entries/naturalism/>.

Plotkin, H. (1997). Darwin Machines and the Nature of Knowledge. Cambridge (MA): Harvard University Press.

Poincaré, H. (2015). The Foundations of Science. Cambridge: Cambridge University Press.

Polkinghorne, J. (2011). Mathematical Reality. In: Polkinghorne, J. (ed.), Meaning in Mathematics. Oxford: Oxford University Press: 27-34.

Pólya, G. (1954). Mathematics and Plausible Reasoning. Princeton: Princeton University Press.

Rodin, A. (2014). Axiomatic Method and Category Theory. Berlin: Springer.

Rosenberg, A. (1996). A Field Guide to Recent Species of Naturalism. The British Journal for the Philosophy of Science, 47: 1-29. 
PENULTIMATE DRAFT - PLEASE CITE THE PUBLISHED VERSION

To appear in: Bangu, S. (ed.), Naturalizing Logico-Mathematical Knowledge, Routledge.

Sage, J. (2004). Truth-Reliability and the Evolution of Human Cognitive Faculties. Philosophical Studies, 117: 95-106.

Sankey, H. (2008). Scientific Realism and the Rationality of Science. Aldershot: Ashgate.

Schechter, J. (2013). Could Evolution Explain Our Reliability about Logic. In: Gendler, T.S., Hawthorne, J. (eds.). Oxford Studies in Epistemology. Volume 4. Oxford: Oxford University Press: 214-239.

Schickore, J. (2014). Scientific Discovery. In: Zalta, E.N. (ed.), The Stanford Encyclopedia of Philosophy, URL $=<$ http://plato.stanford.edu/archives/spr2014/entries/scientificdiscovery/>.

Shapiro, S. (1997). Philosophy of Mathematics: Structure and Ontology. Oxford: Oxford University Press.

Sklar, L. (1981). Do Unborn Hypotheses Have Rights? Pacific Philosophical Quarterly, 62: $17-29$.

Smith, J.M. (2012). Evolution and Logic. In: Dybjer, P., Lindström, S., Palmgren, E., Sundholm, G. (eds.) Epistemology versus Ontology. Dordrecht: Springer: 129-138.

Spelke, E.S. (2011). Natural Number and Natural Geometry. In: Dehaene, S., Brannon, E.M. (eds.), Space, Time and Number in the Brain. Amsterdam: Elsevier: 287-317.

Stanford, P.K. (2006). Exceeding Our Grasp. New York: Oxford University Press.

Turri, J., Klein, P. (2014). Introduction. In: Turri, J., Klein, P. (eds.), Ad Infinitum. New Essays on Epistemological Infinitism. Oxford: Oxford University Press: 1-17.

Vaidya, A. (2016). The Epistemology of Modality. In: Zalta, E.N. (ed.), The Stanford Encyclopedia of Philosophy, URL: <https://plato.stanford.edu/archives/win2016/entries/modality-epistemology/>.

Vlerick, M., Broadbent, A. (2015). Evolution and Epistemic Justification. Dialectica, 69: $185-203$.

Weir, A. (2005). Naturalism Reconsidered. In: Shapiro, S. (ed.), The Oxford Handbook of Philosophy of Mathematics and Logic. Oxford: Oxford University Press: 460-482.

Wilkins, J.S., Griffiths, P.E. (2013). Evolutionary Debunking Arguments in Three Domains: Fact, Value, and Religion. In: Maclaurin, J., Dawes, G. (eds.), A New Science of Religion. New York: Routledge: 133-146.

Williamson, T. (2000). Knowledge and Its Limits. Oxford: Oxford University Press.

Woleński, J. (2012). Naturalism and Genesis of Logic. Studies in Logic, Grammar and Rhetoric, 27: 223-240.

Ye, F. (2011). Strict Finitism and the Logic of Mathematical Applications. Springer: Dordrecht. 